\title{
IGUALDADE E DIGNIDADE HUMANA DAS PESSOAS PORTADORAS DE DEFICIÊNCIA: REFLEXOS DA NOVA LEI DE INCLUSÃO - LEI 13.146/2015 - NO AMBITO DA SAÚDE
}

\author{
EQUALITY AND HUMAN DIGNITY OF PERSONS WITH DISABILITIES: \\ REFLECTIONS OF NEW LAW OF INCLUSION - LAW 13,146 / 2015 - THE \\ HEALTH AREA
}

\author{
${ }^{1}$ Renata Vilaça Pereira \\ ${ }^{2}$ Henrique Rodrigues Lelis
}

\section{RESUMO}

O artigo aborda a lei $n^{\circ} 13.146 / 2015$, denominado Estatuto da Pessoa com Deficiência. Tendo como referencial teórico a obra de Robert Alexy. O problema levantado foi a análise do direito de igualdade e das garantias dos direitos fundamentais pelo Estatuto no âmbito do acesso a saúde. O trabalho foi realizado pelo método dedutivo, por meio do estudo bibliográfico. Observou-se, que a legislação é uma ferramenta importante, no entanto, faz-se necessária uma mudança quanto à concepção das necessidades especiais de cada um, das barreiras a serem vencidas, tanto as físicas como as da discriminação.

Palavras-chave: Inclusão social, Portador de deficiência, Princípio da igualdade, Princípio da dignidade humana

\begin{abstract}
The article discusses the law $n^{\circ} 13.146$ / 2015 called Statute of person with disabilities. The theoretical reference is the work of Robert Alexy. The problem studied was the analysis of the right to equality and guarantees of fundamental rights by the Statute under the access to health. The study was conducted by the deductive method, through bibliographical study. It was noted that the legislation is an important tool, but a change on the design of the special needs of each is needed, the barriers to overcome the physical and the discrimination ones.
\end{abstract}

Keywords: Social inclusion, Handicapped, Principle of equality, Principle of human dignity

\section{Introdução}

\footnotetext{
1 Mestranda em direito pela Universidade de Itaúna. Universidade em Itaúna - UIT, Minas Gerais. Brasil E-mail: renatavilaa@hotmail.com

2 Mestrando em Proteção dos Direitos Fundamentais pela Universidade de Itaúna. Advogado. Universidade em Itaúna - UIT, Minas Gerais. Brasil - E-mail: henriquelelis34@gmail.com
} 
Conceitua-se portador de deficiência física, a partir de uma definição estabelecida pelo Ministério público do Paraná:

\begin{abstract}
pessoas que apresentam necessidades próprias e diferentes que requerem atenção específica em virtude de sua condição de deficiência. Genericamente também são chamados de portadores de necessidades especiais. São pessoas que apresentam significativas diferenças físicas, sensoriais ou intelectuais, decorrentes de fatores inatos ou adquiridos, de caráter permanente, que acarretam dificuldades em sua interação com o meio físico e social (PARANÁ, 2011)
\end{abstract}

Em um levantamento histórico, pode-se considerar a Segunda Guerra Mundial (1939 a 1945) como um importante marco para a obtenção de direitos e garantias de proteção aos portadores de deficiência. Isso porque o pós-guerra foi um período em que vários soldados haviam sobrevivido, porém com diversas sequelas deixadas por ela, estimando um aumento considerado de portadores de deficiência. Deste modo o governo alemão, diante deste novo cenário, iniciou uma busca para possibilitar uma maior igualdade entre estes deficientes e os demais cidadãos (BRUMER; MOCELIN; PAVEI, 2004 p.302).

Contudo, foi a partir da década de 80, que ocorreu uma evolução mais expressiva dos direitos dos portadores de deficiência. No ano de 1982 a ONU aprovou o Programa de Ação Mundial para Pessoas com Deficiência, que estabeleceu uma série de medidas com a finalidade de prevenir, de promover a reabilitação, com o objetivo de conquistar a igualdade com uma participação plena na vida social e no desenvolvimento. Justificava-se assim que as pessoas que se enquadravam neste contexto de deficiência encontravam-se em situação de desvantagem perante as barreiras físicas e sociais impostas a elas (SIERRA, 2010 p.01).

No Brasil, a Constituição Federal de 1.988, tratou de forma especial os portadores de deficiência, o que se verifica claramente em alguns de seus dispositivos. Quando trata da competência, traz o art. 23, inciso II e, XIV art. 24.

Art. 23. É competência comum da União, dos Estados, do Distrito Federal e dos Municípios:

II - cuidar da saúde e assistência pública, da proteção e garantia das pessoas portadoras de deficiência;

Art. 24. Compete à União, aos Estados e ao Distrito Federal legislar concorrentemente sobre:

XIV - proteção e integração social das pessoas portadoras de deficiência;" (BRASIL, 1988).

Ainda, de forma explicita, quando regulamenta a reserva para cargos públicos por meio do art. 37, inciso VIII.

Art. 37. A administração pública direta e indireta de qualquer dos Poderes da União, dos Estados, do Distrito Federal e dos Municípios obedecerá aos princípios de 
legalidade, impessoalidade, moralidade, publicidade e eficiência e, também, ao seguinte:

$[\ldots]$

VIII - a lei reservará percentual dos cargos e empregos públicos para as pessoas portadoras de deficiência e definirá os critérios de sua admissão; (BRASIL, 1988)

No art. 227 consagra a garantia constitucional, visando à proteção aos portadores de deficiência, garantindo acessibilidade e outros direitos importantes para a inclusão social.

\begin{abstract}
Art. 227. É dever da família, da sociedade e do Estado assegurar à criança, ao adolescente e ao jovem, com absoluta prioridade, o direito à vida, à saúde, à alimentação, à educação, ao lazer, à profisssionalização, à cultura, à dignidade, ao respeito, à liberdade e à convivência familiar e comunitária, além de colocá-los a salvo de toda forma de negligência, discriminação, exploração, violência, crueldade e opressão.

(....)

II - criação de programas de prevenção e atendimento especializado para as pessoas portadoras de deficiência física, sensorial ou mental, bem como de integração social do adolescente e do jovem portador de deficiência, mediante o treinamento para o trabalho e a convivência, e a facilitação do acesso aos bens e serviços coletivos, com a eliminação de obstáculos arquitetônicos e de todas as formas de discriminação.

$\S 2^{\circ}$ A lei disporá sobre normas de construção dos logradouros e dos edifícios de uso público e de fabricação de veículos de transporte coletivo, a fim de garantir acesso adequado às pessoas portadoras de deficiência. (BRASIL, 1.988)
\end{abstract}

Verifica-se que, a defesa dos portadores de deficiência prezando pela igualdade e a dignidade humana obteve muitos avanços, porém, muitos obstáculos ainda precisam ser rompidos, quando analisado sob a ótica de uma via de independência física e intelectual. Assim considera Anita Brumer, sobre a legislação brasileira,

\begin{abstract}
No entanto permanecem ainda obstáculos que mantêm a exclusão das pessoas portadoras de deficiência, em termos de uma vida independente, auto-sustentada e plena. A legislação brasileira, até a década de 1980, tinha um caráter basicamente assistencialista e paternalista, ratificando a visão e a prática com as quais geralmente vinham sendo tratadas as questões envolvendo as pessoas portadoras de deficiência. Tais políticas centravam-se, no caso dos deficientes visuais, na organização do ensino e instalação de classes em braille e na adaptação social e reabilitação. Sendo assim, cabia à pessoa adaptar-se ao meio onde vive e não o contrário (BRUMER; MOCELIN; PAVEI, 2004 p.304).
\end{abstract}

Percebe-se que a nova Lei de Inclusão traz a proteção dos deficientes em várias áreas, tratando destes direitos além da esfera da educação, normatizando o direito à cultura e lazer, ao esporte, ao turismo, à assistência social, à moradia, à previdência social, ao transporte e à mobilidade, ao acesso à justiça e à saúde, dentre outros de suma importância para garantir a real igualdade entre as pessoas. 
Tendo como marco teórico a obra de Robert Alexy, fora feito uma analise dos direitos e garantias disponíveis aos portadores de deficiência pela Lei 13.146/2015, buscando compreender qual é a contribuição que a nova norma traz para a efetivação do direito a igualdade nos moldes estabelecidos pela Constituição. Para isto utilizou-se o método dedutivo, usando como técnicas de pesquisa o estudo bibliográfico.

O presente trabalho tem o objetivo de analisar esta nova lei, especificamente no âmbito da saúde, abordando-a com base nos princípios da igualdade e da dignidade humana, consagrados por ela. $\mathrm{O}$ artigo contribui para a análise da nova lei, especialmente quanto a sua finalidade e efetividade no âmbito da saúde.

\section{A Política Pública de inclusão de deficientes no Brasil}

A partir das Constituições Brasileiras é possível fazer uma evolução histórica no que tange a defesa dos portadores de deficiência. Verifica-se desde a Constituição de 1934, traços que diferenciavam este grupo de pessoas, que em seu artigo 138 assegurava o amparo ao desvalido, e incumbia o dever ao Município, Estado e União, de criar serviços especializados e um serviço de orientação por meio dos serviços sociais (DICHER; TREVISAN, 2014 p.17).

Já as Constituições de 1937, 1946 e 1967, se mantiveram silenciosas, nenhuma inovação foi proposta neste período, e que, verifica-se apenas, com a emenda $\mathrm{n}^{\circ} 12$ à constituição de 1967, que trazia uma manifestação um pouco mais concreta desta proteção (DICHER; TREVISAN, 2014 p.17).

Contudo o marco mais importante se deu com a promulgação da Constituição Federal de 1988 que trouxe de forma mais clara, os objetivos de uma política nacional de proteção aos portadores de deficiência e os deveres do Estado em criar e executar estas ações.

A partir da Constituição outras normatizações vieram para melhor definir, como a Lei 7.853/89 que criou a Coordenadoria Nacional para a Integração da Pessoa Portadora de Deficiência, e demais leis que objetivavam disciplinar em cada área a politica de proteção (DICHER; TREVISAN, 2014 p.18).

Neste contexto o Decreto 3.298/99 dispõe sobre a Política Nacional para a Integração da Pessoa Portadora de Deficiência, cujo objetivo é criar conjuntos de regras para garantir a plena integração social. 
Percebe-se que uma política de inclusão não compreende somente normas de cunho inibitórias, mas, fazem-se necessárias normas afirmativas, que impõem ao Estado ações que propiciem a igualdade entre as pessoas.

Para se chegar a um a vinculação substancial do legislador, é necessário interpretar a fórmula "o igual deve ser tratado igualmente; o desigual, desigualmente" não como uma exigência dirigida ao seu conteúdo, ou seja, não no sentido de um dever formal, mas de um dever material de igualdade. (ALEXY, 2015 p.399)

Maria Paula Bucci define políticas públicas como:

“... o programa de ação governamental que resulta de um processo ou conjunto de processos juridicamente regulados - processo eleitoral, processo de planejamento, processo de governo, processo orçamentário, processo legislativo, processo administrativo, processo judicial - visando coordenar os meios à disposição do Estado e as atividades privadas, para a realização de objetivos socialmente relevantes e politicamente determinados. Como tipo ideal, política pública deve visar a realização de objetivos definidos, expressando a seleção de prioridades, a reserva de meios necessários à sua consecução e o intervalo de tempo em que se espera o atingimento dos resultados.” (BUCCI, 2006, p 39).

No Brasil, um forte debate se ergueu sobre a educação inclusiva, com discussões subsidiadas pela comunidade escolar e participação popular acerca das políticas implantadas e ainda em criação, pós-discussão na área da educação, agora, faz-se necessário evoluir nas discussões frente às outras áreas, apesar de já existir uma legislação normatizando cada uma delas, pouco se percebe um movimento de discussão e de mobilização.

De fato, verifica-se que mesmo, com todo amparo das normatizações já previstas no ordenamento, a efetividade das ações dependerá de uma rede complexa, que será composta por parte da sociedade e ainda pelo Estado, com a participação de cada setor, cada qual em sua função, mas sempre de forma cooperativa. Neste sentido, anota Toldrá citando Quintão:

No entanto, mesmo considerando-se a pertinência das leis, isso não garante efeitos imediatos. A viabilidade das mesmas dependerá de uma rede complexa que exigirá de todos os envolvidos direta ou indiretamente uma (re)posição, uma (re)visão das referências em que se baseiam os conceitos e os preconceitos da sociedade, os quais devem ter repercussão no âmbito político, econômico e institucional. Quintão (2005, apud TOLDRÁ, 2009 p.115).

\subsection{A nova Lei de inclusão - Lei $n^{\circ} 13.146$ de 06 de julho de 2015}

A nova lei de inclusão recebe o nome de Estatuto da Pessoa com Deficiência, regulamenta as ações e serviços na esfera nacional, assegurando às pessoas com deficiência, o exercício dos seus direitos em condições de igualdade com as demais. Isto pois, conforme explica Alexy (2015 p 399), o enunciado geral de igualdade, determina que sua interpretação 
e exigência seja dirigida ao conteúdo da norma, ou seja, não em um dever formal, mas de um dever material de igualdade.

Recorre-se no presente trabalho ao conceito de arbítrio, para concluir que as discriminações autorizadas devem ser aquelas que não sejam arbitrárias, que sejam dotadas de critério com fundamento material bastante no âmbito da dignidade da pessoa humana. De fato, não se pode procurar tal critério em qualquer lugar. Ele somente será encontrado num específico e determinado horizonte de aplicação da igualdade, cujas evidências somente serão reveladas na globalidade das circunstâncias fáticas do caso. É preciso, enfim, encontrar os limites jurídicos de uma esfera especial de justiça. (BARBOSA, 2015, P 1061)

Busca-se a liberdade dos portadores de deficiência, que muitas vezes se veem limitados em seus atos pela desigualdade fática, principalmente no que tange a acessibilidade e a igualdade de tratamento.

\begin{abstract}
A lei federal 13.146 de 2015 é um marco na defesa e proteção da pessoa com deficiência e instituiu a Lei Brasileira de Inclusão, também conhecida como Estatuto da Pessoa com Deficiência e tem por objetivo principal efetivar a inclusão social e a cidadania da pessoa com deficiência, através de mecanismos legais que visam assegurar e promover o exercício de direitos e liberdades fundamentais, pela pessoa com deficiência, em condições de igualdade com as demais pessoas. (Vicente; Aguado, 2015 P 96)
\end{abstract}

A vigência da nova lei ocorreu a partir de 180 dias de sua publicação oficial, que ocorreu em 07.07.2015, e disciplina diversas questões relativas à pessoa com deficiência, em harmonia com normas internacionais que tratam sobre o tema.

O referido Estatuto possui base a partir do Decreto legislativo $n^{\circ} 186$ de 09 de junho de 2008 , no $\S 3^{\circ}$ do art. $5^{\circ}$ da Constituição Federal e pelo Decreto $n^{\circ} 6.949$ de 25 de agosto de 2009.

Assim constitui-se a definição de deficiência trazida pela Lei 13.146/2015

Art. $2^{\underline{o}}$ Considera-se pessoa com deficiência aquela que tem impedimento de longo prazo de natureza física, mental, intelectual ou sensorial, o qual, em interação com uma ou mais barreiras, pode obstruir sua participação plena e efetiva na sociedade em igualdade de condições com as demais pessoas (BRASIL, 2015).

O referido Estatuto incumbe ao poder público criar instrumentos que possibilitem avaliar e constatar a deficiência, além de trazer definições de acessibilidade, desenho universal, tecnologia assistiva ou ajuda técnica, barreiras, comunicação, adaptações razoáveis, dentre outras ações com o objetivo de amparar na criação das políticas de proteção e inserção social.

A lei ainda destaca em seu capitulo II, o princípio da igualdade, quando em seu art. 
$4^{\circ}$, dispõe que toda pessoa com deficiência tem direito à igualdade de oportunidades, que será garantida pelas normatizações impostas, considerando além da questão de acessibilidade, o caráter proibitivo da discriminação. Neste sentido, a compreensão do princípio da igualdade deve ser dirigida ao conteúdo da norma e não a sua forma, caracterizando-se pela concretização de um dever material de igualdade. (ALEXY, 2015 p.399)

A igualdade abrange também a capacidade civil da pessoa, que por meio do art. $6^{\circ}$, altera a relação de capacidade civil imposta pelo código civil de 2002.

\footnotetext{
Art. $6^{-}$A deficiência não afeta a plena capacidade civil da pessoa, inclusive para: I - casar-se e constituir união estável; II - exercer direitos sexuais e reprodutivos;

III - exercer o direito de decidir sobre o número de filhos e de ter acesso a informações adequadas sobre reprodução e planejamento familiar;

IV - conservar sua fertilidade, sendo vedada a esterilização compulsória;

$\mathrm{V}$ - exercer o direito à família e à convivência familiar e comunitária; e

VI - exercer o direito à guarda, à tutela, à curatela e à adoção, como adotante ou adotando, em igualdade de oportunidades com as demais pessoas. (BRASIL, 2015)
}

Considerando o art. $3^{\circ}$ do Código Civil de 2002, eram absolutamente incapazes: os menores de dezesseis anos; os que, por enfermidade ou deficiência mental, não tivessem o necessário discernimento para a prática desses atos; os que, mesmo por causa transitória, não pudessem exprimir sua vontade. Com o advento da Lei 13.146/2015 apenas os menores de dezesseis anos compõe o rol do art. do Código Civil de 2002 (GARCIA, 2015 p.73-79).

Outra alteração corresponde ao art. $4^{\circ}$ do Código Civil de 2002, que anteriormente, eram relativamente incapazes: os maiores de dezesseis e menores de dezoito anos; os ébrios habituais, os viciados em tóxicos, e os que, por deficiência mental, tivessem o discernimento reduzido; os excepcionais, sem desenvolvimento mental completo; os pródigos, com a nova lei passa ser considerados somente: os maiores de dezesseis e menores de dezoito anos; os ébrios habituais e os viciados em tóxicos; aqueles que, por causa transitória ou permanente, não puderem exprimir sua vontade; os pródigos (art. $4^{\text {o }}$ do Código Civil de 2002, com redação dada pela Lei 13.146/2015) (GARCIA, 2015 p.73-79).

Além de impor o dever à União, Estado e Município, quanto à efetivação dos direitos garantidos aos portadores de deficiência, também chama à responsabilidade à família e toda sociedade, e assim, a inclusão social passa a ser compartilhada entre governantes, e toda sociedade, que também possui seu papel estabelecido nesta Lei.

Ainda contempla em seu título II, dos direitos fundamentais, a relevância do princípio da dignidade humana, e impõe de forma clara ao poder público, a obrigação de garantir 
este princípio. "Art. 10.Compete ao poder público garantir a dignidade da pessoa com deficiência ao longo de toda a vida" (BRASIL, 2015).

O nosso enfoque especial, se encontra no Capítulo III, da referida Lei, quando dispõe sobre o direito à saúde do portador de deficiência, o que aprofundaremos mais a frente.

\title{
2. O direito do portador de deficiência na esfera da saúde a partir do Estatuto da Pessoa com Deficiência
}

A lei orgânica do SUS traz como um dos princípios e diretrizes, a igualdade de assistência, obviamente que, quando se trata deste princípio faz-se necessário reconhecer as diferenças existentes, neste caso o portador de deficiência.

\begin{abstract}
Como se vê, em lugar da concepção «estática» da igualdade extraída das revoluções francesa e americana, cuida-se nos dias atuais de se consolidar a noção de igualdade material ou substancial, que, longe de se apegar ao formalismo e à abstração da concepção igualitária do pensamento liberal oitocentista, recomenda, inversamente, uma noção «dinâmica», «militante» de igualdade, na qual necessariamente são devidamente pesadas e avaliadas as desigualdades concretas existentes na sociedade, de sorte que as situações desiguais sejam tratadas de maneira dessemelhante, evitando-se assim o aprofundamento e a perpetuação de desigualdades engendradas pela própria sociedade. (GOMES, 2015, p.2).
\end{abstract}

Neste sentido a Constituição Federal e a legislação infraconstitucional que normatizam o sistema único de saúde, corroboram com a Política Nacional para a Integração da Pessoa Portadora de Deficiência (PNIPPD), zelando pelo princípio da universalidade de acesso, equidade, e integralidade.

A legislação existente trazia avanços importantes para a defesa dos direitos dos portadores de deficiência, porém fazia-se necessário uma legislação mais específica no âmbito da saúde, por isso com a Portaria 818/GM do Ministério da Saúde/2001, a seção I do Decreto 3.298/99 referente à saúde e ainda Lei 9.656 de 03 de junho de 1998, possibilitou normatizar de forma mais clara e detalhada os serviços de saúde, inclusive os privados, na política de proteção ao deficiente.

No art. 18, o EPCD reafirmou diretrizes necessárias à atenção integral à saúde da pessoa com deficiência, definindo seu atendimento em todos os níveis de complexidade, por intermédio do SUS, garantido acesso universal e igualitário. A prevenção e a diminuição de riscos foi um dos pontos focados pela norma em comento, a fim de evitar o surgimento ou agravamento de deficiências e doenças, como a necessidade de se realizar diagnóstico e intervenção precoce, realizados por equipe multidisciplinar; serviços de habilitação e de reabilitação sempre que necessários, para qualquer tipo de deficiência, inclusive para a manutenção da melhor condição de saúde e qualidade de vida; atendimento domiciliar multidisciplinar, tratamento ambulatorial e internação; campanhas de vacinação; atendimento psicológico, inclusive para seus familiares e atendentes pessoais; respeito 
à especificidade, à identidade de gênero e à orientação sexual da pessoa com deficiência; promoção de estratégias de capacitação permanente das equipes que atuam no SUS, em todos os níveis de atenção, no atendimento à pessoa com deficiência, bem como orientação a seus atendentes pessoais. (Araujo; Costa Filho, 2015 P 06)

Na Lei 13.146/2015, o capítulo III intitulado Do Direito à saúde, dispõe de uma normatização no âmbito das políticas públicas e também regulamenta o setor privado, quanto às obrigações no atendimento à pessoa com deficiência.

Além de garantir o atendimento integral, ou seja, em todos os níveis de complexidade, considerando assim a prevenção até a urgência, garante também a participação da pessoa com deficiência na criação das políticas de saúde destinadas a elas.

A lei assegura questões básicas, mas que não eram regulamentadas, como por exemplo, as definições de serviços de habilitação e reabilitação; acompanhamento integral em atendimento durante a gravidez; a garantia de atendimento adequado quando o mesmo não puder ser realizado na cidade de residência, estabelecendo transporte adequado inclusive para seu acompanhante; garantia de acompanhante durante o período de internação.

Especificamente no setor privado, veda a discriminação e garante a igualdade na cobrança de valores por planos e seguros privados de saúde, não se justificando um pagamento diferenciado em razão de sua condição.

O direito à informação, como em todas as outras áreas é considerado como fundamental, e dispõe que as mesmas deverão ser prestadas por meio de recursos de tecnologia assistiva, abarcando todas as formas de comunicação previstas no inciso $\mathrm{V}$ do art. $3^{\circ}$ do Estatuto.

Quanto à tecnologia assistiva, entende-se por,

Tecnologia Assistiva é uma área do conhecimento, de característica interdisciplinar, que engloba produtos, recursos, metodologias, estratégias, práticas e serviços que objetivam promover a funcionalidade, relacionada à atividade e participação, de pessoas com deficiência, incapacidades ou mobilidade reduzida, visando sua autonomia, independência, qualidade de vida e inclusão social. (BRASIL, 2009).

Quanto à acessibilidade todos os prestadores de saúde, público ou privado, devem estar adaptados conforme legislação, atendendo a todos os tipos de deficiência. Percebe-se que quanto à acessibilidade, existe uma grande dificuldade, tanto nos serviços públicos quanto os privados, considerando o despreparo inclusive do poder público, para recepcionar estas pessoas. 
Importante ressaltar que, quando se fala em acessibilidade, a própria lei, traz a seguinte definição:

Art. 53. A acessibilidade é direito que garante à pessoa com deficiência ou com mobilidade reduzida viver de forma independente e exercer seus direitos de cidadania e de participação social (BRASIL, 2015).

Por fim, este capítulo, atribui à obrigatoriedade de notificar violência sofrida pela pessoa com deficiência, considerando esta violência praticada como qualquer ação ou omissão, em local público ou privado, causando a morte, danos físico ou psicológico. Outras normatizações contidas nas disposições gerais desta lei também contribuem na regulamentação na área da saúde.

\section{A consagração do Princípio da Igualdade e da Dignidade da Pessoa Humana}

A partir da teoria dos direitos fundamentais, estruturada por Robert Alexy, verificase que, para cada direito fundamental, existe uma norma para garantir este direito; e assim, como quando utilizadas em outras ciências, possuem um sentido amplo, e podem ser expressas por várias formas (ALEXY, 2015 p.50).

No que tange às normas de direitos fundamentais, faz-se necessário à distinção entre regras e princípios, constituindo um elemento fundamental na dogmática dos "direitos de liberdade e igualdade, assim como os direitos de proteção, a organização e procedimento e a prestação" (ALEXY, 2015 p. 85)

Ressalta-se em primeiro momento, a definição dada por Robert Alexy, acerca dos princípios no ordenamento jurídico:

princípios são normas que ordenam que algo seja realizado em uma medida tão ampla quanto possível relativamente a possibilidades fáticas ou jurídicas. Princípios são, portanto, mandamentos de otimização, Como tais, eles podem ser preenchidos em graus distintos (ALEXY, 1999 p.74).

Quando Alexy aborda o dever de igualdade na criação do direito, explica que:

[...] o enunciado da igualdade não pode exigir a igualdade de todas as características naturais e todas as condições fáticas nas quais o indivíduo se encontre. Diferenças em relação à saúde, à inteligência e beleza podem ser talvez um pouco relativizada, mas sua eliminação se depara com limites naturais. [....] o enunciado geral de igualdade, dirigido ao legislador, não pode exigir que todos sejam tratados exatamente da mesma forma, ou que todos devam ser iguais em todos os aspectos. Por outro lado, para ter algum conteúdo, ele não pode permitir toda e qualquer diferenciação e toda e 
qualquer distinção. È necessário questionar como é possível encontrar um meio termo entre dois extremos (ALEXY, 2015, p. 397)

Desta forma a Lei de Inclusão garante a igualdade, possibilitando que o desigual seja tratado de forma desigual, e deste modo possibilitando e garantindo o acesso à dignidade necessária para o mínimo existencial.

$\mathrm{Na}$ área da saúde, para garantir esta igualdade, ao poder público e aos serviços privados de assistência a saúde, a nova lei impôs diversas mudanças, tanto em sua estrutura física como na humanização do atendimento, já que, pela debilidade de cada tipo de deficiência, sem estas exigências legais, quanto ao tratamento diferenciado, esta igualdade perante as outras pessoas, era quase impossível de ser alcançada.

\begin{abstract}
As estruturas da desigualdade podem ser, se não modificadas, bastante perturbadas na sua inércia conservadora, mediante processos jurídico-institucionais bem articulados. O Brasil é um país com abundância de recursos minerais, terra aproveitável para agricultura, recursos hídricos, sem histórico de conflitos étnicos ou religiosos, ou fatores desse gênero de desagregação social, com exceção da desigualdade social e econômica, enraizada na longa e persistente história da escravidão e sua obra, na expressão de Joaquim Nabuco. A condição de atraso e pobreza não pode ser tomada como uma condenação, mas encarada como problema que pode ser superado, na perspectiva da ação dos governos e da sociedade, no limiar de um período de crescimento e desenvolvimento que permite acreditar na sustentabilidade das conquistas sociais e dos avanços institucionais. (BUCCI, 2013 p.26)
\end{abstract}

Como descrito por Alexy, faz-se necessário que o legislativo, trate de forma desigual os portadores de deficientes, para que possa, de forma concreta atingir e garantir a igualdade determinada pela norma (ALEXY, 2015 p. 397)

No Brasil, o princípio da dignidade da pessoa humana, é disposto no art. $1^{\circ}$ da Constituição Federal da República,

Art. $1^{\circ}$ A República Federativa do Brasil, formada pela união indissolúvel dos Estados e Municípios e do Distrito Federal, constitui-se em Estado Democrático de Direito e tem como fundamentos:

I - a soberania;

II - a cidadania;

III - a dignidade da pessoa humana; (BRASIL, 1988, p.1)

Ainda no art. $3^{\circ}$ voltou-se à dignificação do homem,

Art. $3^{\circ}$ Constituem objetivos fundamentais da República Federativa do Brasil: I - construir uma sociedade livre, justa e solidária;

II - garantir o desenvolvimento nacional;

III - erradicar a pobreza e a marginalização e reduzir as desigualdades sociais e regionais; 
IV - promover o bem de todos, sem preconceitos de origem, raça, sexo, cor, idade e quaisquer outras formas de discriminação (BRASIL, 1988 p. 1).

Como podemos verificar, quando analisamos a nova lei de inclusão, denominado Estatuto da pessoa com deficiência, fica claro a importância dada a estes dois princípios, o da dignidade da pessoa humana e da igualdade.

Esta nova lei reconhece o princípio da dignidade humana, por meio da proteção dos direitos à pessoa portadora de deficiência. O princípio da dignidade humana constitui hoje, na elaboração da normatização, neste caso o referido Estatuto, como a espinha dorsal, base fundamental na garantia do direito do homem.

A adoção do princípio da dignidade da pessoa humana atribui ao Estado à obrigação de criar e programar políticas públicas, que incluam todas as pessoas, em um equilíbrio de igualdade, possibilitando o acesso universal a todos os bens e serviços que propiciem uma vida com dignidade.

A partir da nova Constituição, estabeleceu-se uma nova forma de pensar o princípio da dignidade, emergindo a tentativa de um direito mais justo, neste sentido preceitua Carmem Lúcia Antunes Rocha,

Contra todas as formas de degradação humana emergiu como imposição do Direito justo o princípio da dignidade da pessoa humana. A degradação encontra sempre novas formas de se manifestar; o Direito há de formular, paralelamente, novas formas de se concretizar, assegurando que a Justiça não se compadeça do aviltamento do homem ou da desumanização da convivência (ROCHA, 1999 p. 25).

Ainda nas palavras de Carmem Lúcia, verifica-se que,

a dignidade humana independe de merecimento pessoal ou social. Não se há de ser mister ter de fazer por merecê-la, pois ela é inerente à vida e, nessa contingência, é um direito pré -estatal (ROCHA, 1999 p. 25).

A lei ainda, além da imposição da obrigação ao poder público e aos privados, de ações concretas, traz também quanto à discriminação, sofrida por este grupo de pessoas, não somente pelas manifestações de outros indivíduos, mas também, no momento em que se encontra impossibilitado o acesso igualitário aos bens e serviços oferecidos para todos. A exclusão social imposta às pessoas portadoras de deficiência fere, sem dúvida, um dos princípios mais importantes, o da dignidade humana. Assim compreende Carmem Lúcia Rocha:

Toda forma de preconceito é indigna e a sua manifestação é antijurídica. Lesa-se por ela o princípio enfatizado neste estudo. A exclusão social é fator de indignidade e de indignação que põe o homem à margem de sua própria sociedade, carente de seu respeito próprio e de sua honorabilidade social, porque se põe como alguém que não é 
útil e, note-se aqui, no sentido utilitário, de não dar lucro, de não ser fonte de utilidade segundo os paradigmas de uma economia que rejeita o homem (ROCHA, 1999 p.37).

Considerando o exposto, verifica-se uma evolução dos direitos das pessoas portadores de deficiência, configurando a importância desta nova lei, consagrando o princípio da igualdade e da dignidade humana. Evidencia-se a concretização do princípio da isonomia e do princípio da dignidade da pessoa humana, no que tange ao fim das barreiras visíveis, proporcionando o acesso a todos locais para exercer sua cidadania, por meio de direitos iguais na cultura, lazer, educação e saúde. A acessibilidade alcançada pelo Estatuto representa efetivamente a consagração do princípio da igualdade e da dignidade humana.

\section{Considerações finais}

Esta ampliação dada à nova lei de inclusão renova a esperança, na concretização da igualdade entre a pessoa portadora de deficiência e as demais, porém sabe-se que muito ainda deve ser feito. Uma mudança concreta deve ser iniciada, primeiramente quanto ao pensamento humano, sobretudo no que tange à discriminação desta condição.

A acessibilidade ora apresentada, não configura tão somente, quanto às barreiras físicas, mas a própria mentalidade, que impede que um olhar diferenciado seja voltado para este grupo de pessoas. Talvez o preconceito seja a maior barreira ente todas elas, pois muitas vezes, é o que impede o avanço da quebra de outras limitações impostas.

O poder público, sobretudo, necessita de uma nova concepção, a fim de ajustar sua própria sede, para melhor acolher os deficientes, pois diante da realidade, o que se encontra é um despreparo, tanto na questão dos acessos físicos, impossibilitando a entrada e a locomoção e ainda, quanto ao próprio atendimento humano, que não estão preparados para atender todos os tipos de deficiência.

A nova lei consagra o princípio da igualdade no momento em que, estabelece diretrizes de apoio à pessoa portadora de deficiência, considerando a desigualdade de cada deficiência, objetivando o equilíbrio, entre os portadores e as demais pessoas usuárias de bens e serviços.

Ainda, no momento em que presa pela vida, a honra e a dignidade no atendimento e no cotidiano dos deficientes, proporcionando a liberdade, o direito de ir e vir, a prioridade de atendimento em detrimento da condição de vulnerável, condição de sobrevivência, com 
parâmetros do mínimo existencial, e ainda, proporciona uma dignidade psicológica, de independência e auto estima, consagra pela nova lei, o princípio da dignidade humana.

As diretrizes apresentadas pela nova lei trazem consigo a garantia de uma igualdade e da dignidade humana, porém, o grande debate que se faz necessário é, quanto à efetivação desta política, que apesar de já possuir uma série de leis que regulam o assunto, não é possível visualizar sua aplicação na sociedade. Percebe-se muitas vezes um descumprimento pelo próprio poder público, ora em destaque, responsável por criar e estabelecer estas políticas. 


\section{Referências}

ALEXY, R. Teoria dos direitos fundamentais. Tradução de Virgílio Afonso da Silva. $2^{\circ}$ ed. São Paulo: Malheiros, 2015.

ALEXY, R.. Direitos Fundamentais no Estado Constitucional Democrático. Revista de Direito Administrativo, Rio de Janeiro, 217, jul./set. 1999.

ARAUJO, Luiz Alberto David; DA COSTA FILHO, Waldir Macieira. O Estatuto da Pessoa com Deficiência-EPCD (Lei 13.146, de 06.07. 2015): algumas novidades. Revista dos Tribunais|vol, v. 962, n. 2015, p. 65-80, 2015.

BARBOSA, Gleidson de Oliveira Grisoste. O princípio da igualdade no Supremo Tribunal Federal Brasileiro. In Revista Jurídica Luso brasileira. Publicação do Centro de Investigação de Direito Privado da Faculdade de Direito da Universidade de Lisboa (CIDP). $\mathrm{n}^{\circ}$ 1. Ano 1. 2015.

BAPTISTA, R. S.; Inacia Sátiro Xavier de França, PAGLIUCA, L. M. F.. Política de inclusão do portador de deficiência:possibilidades e limites, Acta Paul Enferm, v. 21, n. 1, 2008.

BRASIL. Câmara dos Deputados. Constituição da República Federativa do Brasil de 1988.35 ed. 2012.

BRASIL. Lei 8.080/90 de 19 de setembro de 1990. Dispõe sobre as condições para a promoção, proteção e recuperação da saúde, a organização e o funcionamento dos serviços correspondentes e dá outras providências. Disponível em: <http://www.saude.mg.gov.br/index.php?option=com_gmg\&controller=document\&id=7576 $>$ Acesso em: 15 de dez. 2015.

BRASIL. Lei no 10.406, de 10 de janeiro de 2002. Institui o Código Civil. Disponível em: http://www.planalto.gov.br/ccivil_03/leis/2002/L10406.htm. Acesso em: 15 de dez. de 2015.

BRASIL. Lei 13.146/2015 de 06 de julho de 2015. Institui a Lei Brasileira de Inclusão da Pessoa com Deficiência (Estatuto da Pessoa com Deficiência). Disponível em : 
http://www.planalto.gov.br/ccivil_03/_Ato2015-2018/2015/Lei/L13146.htm. Acesso em: 15 de dez. de 2015.

BRASIL. Subsecretaria Nacional de Promoção dos Direitos da Pessoa com Deficiência. Comitê deAjudas Técnicas. Tecnologia Assistiva . Brasília: CORDE, 2009.

BRUMER, A.; MOCELIN, D. G. ; PAVEI, K.. Saindo da "escuridão": perspectivas da inclusão social, econômica, cultural e política dos portadores de deficiência visual em Porto Alegre. Sociologias. Porto Alegre, ano 6, nº 11, jan/jun 2004.

BUCCI, Maria Paula Dallari. Fundamentos para uma teoria jurídica das políticas públicas.São Paulo: Saraiva, 2013.

DICHER, M.; TREVISAM, E.. A jornada histórica da pessoa com deficiência: inclusão como exercício do direito à dignidade da pessoa humana. Disponível em http://publicadireito.com.br/artigos/?cod=572f88dee7e2502b. Acesso em: 10/02/2016.

D’OLIVEIRA, M. C. B.. Breve análise do princípio da isonomia. Revista Processus, ano 1, n. 01, p. 22-31, 2010.

FREITAS, L.B. de L., PAULON, S.M., PINHO, G.S., Documento subsidiário à política de inclusão. Brasília : Ministério da Educação, Secretaria de Educação Especial,2005.

GARCIA, Gustavo Filipe Barbosa. Introdução ao estudo do direito: teoria geral do direito. 3. ed. São Paulo: Método, 2015.

GOMES, Joaquim B. Barbosa. Instrumentos e métodos de mitigação da desigualdade em direito constitucional e internacional. Rio de Janeiro, Disponível em www. mre. gov. br. Acessado em 15 de janeiro de 2016, v. 4, n. 12, p. 2003, 2000.

PARANÁ. Ministério Público do Estado do Paraná - MPPR. Conceito de Deficiência. CAOPIPPD - Área da Pessoa Portadora de Deficiência. 2011. Disponível em: http://www.ppd.mppr.mp.br/modules/conteudo/conteudo.php?conteudo=41. Acesso em 15 de janeiro de 2016.

ROCHA, C. L. A.. O princípio da dignidade da pessoa humana e a exclusão social. Revista Interesse Público, n4, 1999.

SANTOS, F.. A efetividade dos direitos fundamentais sociais e o controle das políticas públicas à luz da teoria dos princípios. Revista de Informação Legislativa, $n^{\circ} 175$, jul/set 
2007.

SIERRA, V. M.. Rompendo o estigma da incapacidade: a evolução dos direitos para de crianças e adolescentes com deficiência. Âmbito Jurídico, Rio Grande, v. 13, n. 73, fev.

2010. Disponível em: <http://www.ambitojuridico.com.br/site/index.php?n_link=revista_artigos_leitura\&artigo_id=7197>. Acesso em 17 jan. 2016.

TOLDRÁ, R. C. Políticas afirmativas: opinião das pessoas com deficiência acerca da legislação de reserva de vagas no mercado de trabalho. Rev. Ter. Ocup. Univ. São Paulo, v. 20, n. 2, p. 110- 117, maio/ago. 2009.

VICENTE, Maysa Caliman; AGUADO, Juventino de Castro. A proteção e defesa da pessoa com deficiência: A evolução da legislação até a promulgação da lei 13.146 de 2015 e a garantia do direito à saúde. In: Anais do Congresso Brasileiro de Processo Coletivo e Cidadania. 2016. 